\title{
p-p and p-d Elastic and Inelastic Scattering in the High t-Region in che New Internal Target Laboratory
}

\author{
v. Bartenev, A, Kuznetsov, B. Morazov, \\ V. Nikitin, Y. Pilipenko, and L. Zolin \\ Jbint Instituce for Nuclesr Research (Dubna) \\ and
}

E. Malamud and R. Yamada

Nationa I Accelerator Zaboratory

and

F. Loeffler, E. Shibata, K. Stanfield and Y. Tang

. Purdue University

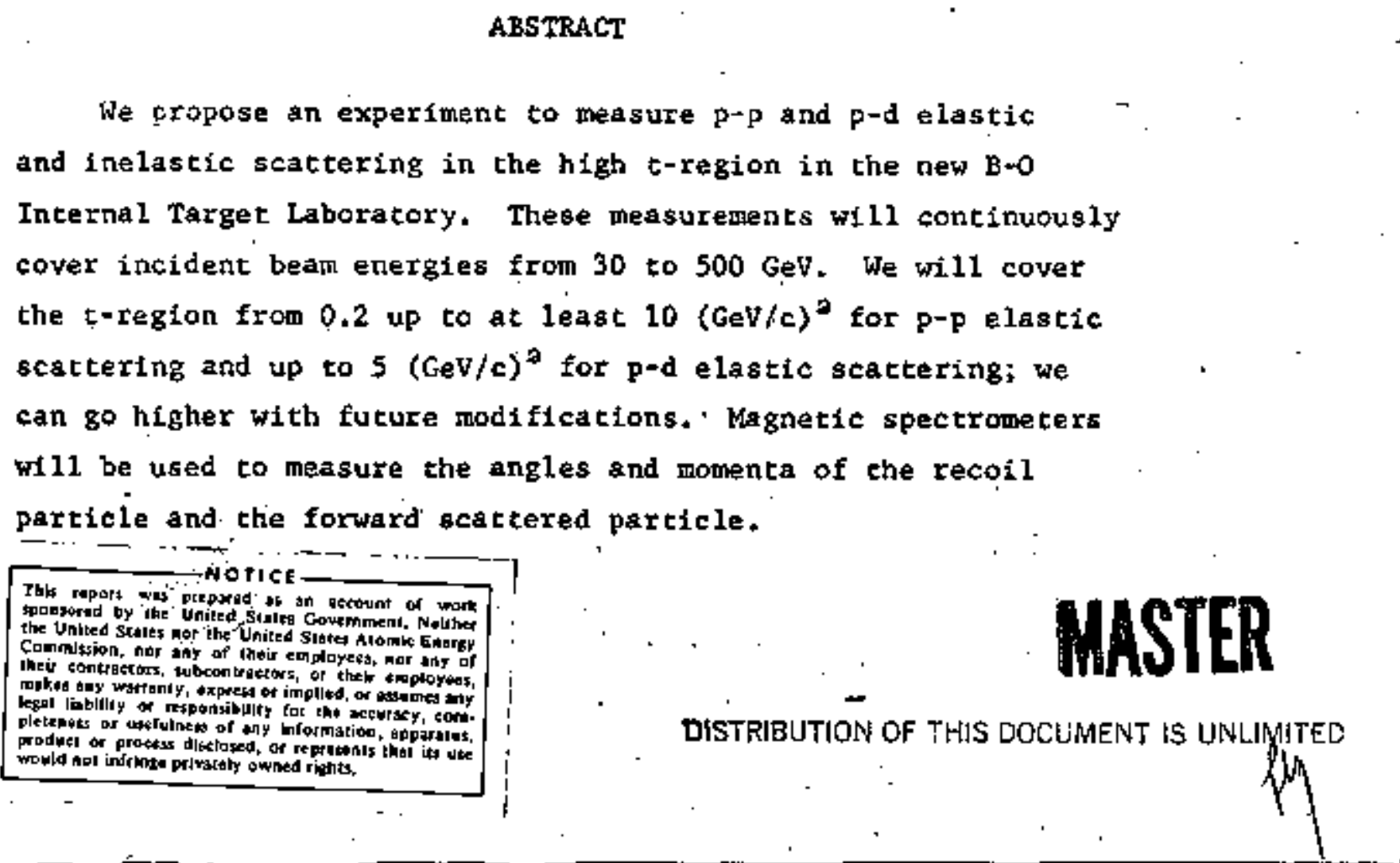




\section{DISCLAIMER}

This report was prepared as an account of work sponsored by an agency of the United States Government. Neither the United States Government nor any agency Thereot, nor any of their employees, makes any warranty, express or implied, or assumes any legal liability or responsibility for the accuracy, completeness, or usefulness of any information, apparatus, product, or process disclosed, or represents that its use would not infringe privately owned rights. Reference herein to any specific commercial product, process, or service by trade name, trademark, manufacturer, or otherwise does not necessarily constitute or imply its endorsement, recommendation, or favoring by the United States Government or any agency thereof. The views and opinions of authors expressed herein do not necessarlly state or reflect those of the United States Government or any agency thereof. 


\section{DISCLAIMER}

Portions of this document may be illegible in electronic image products. Images are produced from the best available original document. 


\section{Introduction}

Small angle p-p elastic scottering up to 0.2 (GeV/c) has been measured at the C-O straight section by Experiment 36. The slope parameter and the real part of the scattering amplitude for p-p elastic scattering and the total cross seccion were measured. 1 Some of the same parameters for p-d elastic scattering were also measured ${ }^{2}$ and will be measured in much more detall in the near future by Experiment 186.

"In these measurements solid state detectors are used to define the scattering angle and the energy of the recoll particles for determination of elastic events. These measurenents are limited to the very sma11 t-range due to thickness of the soldd state detector which defflnes the maximum detectable energy of the recoil particles.

We propose to measure elastic scattering from where the above experiment stops, up to about $10(\mathrm{GeV} / \mathrm{c})^{2}$, snd possibly into higher t-regions. The energy range covered will be from about $30 \mathrm{GeV}$ up to $500 \mathrm{GeV}$. In the internal target area we have the added advantage that all incident energies aze readily available up to the maximum machine energy. The s-dependence of the reactioas can be determined easily. At low-t where only the recoil particle is measuzed, different energy data will be taken within the same main ring cycle. At high-t, where both recoil and forward scattered protons are measured, data will be, taken by moving the magnets remotely within a short time.

Most of the equipment which we propose can be used for many fucure. experiments, including these same experiments extended to $1000 \mathrm{GeV}$ with the proposed energy doubler. Likewise, when the new internal target area 
is built, it will be used by many other experiments, and will be the first experimental axea for the beath from the energy doubler.

\section{Physics}

Elastic scatteriag may be divided into regions according to the $t$-range covered as shown in Table I for p-p elastic scattering and Table 2 for p-d elastic scattering. The data are divided according to their phenonenological behavior. Regions $l$ and 2, for $p-p$ and $p-d$, will be measured in Experiment 36 and 186. We will extend these measurements in the new internal carget laboratory to higher $t$ and higher s-regions.

\section{1 patcering}

Elastic p-p scattering at very high energy and at high-t up to $5(\mathrm{GeV} / \mathrm{c})^{2}$ has been theasured at the ISR and reported ${ }^{3}$ ss bhown in F1g. 1 . There is extensive data below $30 \mathrm{GeV}$, but there is not enough data between $30 \mathrm{GeV}$ and ISR energies. We can measure elastic scattering in the NAL energy range and thereby provide this fundamental data in the gap between $30 \mathrm{GeV}$ and ISR energies. -

The most prominent feature of the ISR data may be the dip around 1.3 (GeV/c $)^{2}$ as shown in Fig. 1. This had not been observed at lowex energies, although a kink in the cross sections exists there. This dip was predicted by many models for the asymptotic limit. ${ }^{4}$ According to theory, this dip is partially filled in at low energy where the real part of the scatering amplitude is large. Preliminary data from Experiment 36 finds the ratio of the real to the imaginary part of the scattering amplitude to be less than $10 \%$ around $200 \mathrm{GeV}$ and up (Fig. 2). Therefore, 
we should be able to observe this dip and its s-dependence at MAL energies. Its relation to the real part of the scattering amplitude will be studied.

The theory also predicts another dip around $|\mathrm{t}|=5 \sim 8(\mathrm{GeV} / \mathrm{c})^{2}$. If this dip exists, our counting rate is high enough to find it. The internal target has an advantage over the ISR as far as counting rate is concerned. As is deacribed in a memo by $\mathrm{E}$. Malamud, 5 the interaction rate per aecond for $\sigma=40 \mathrm{mb}$ is $10^{4}$ for the ISR with a 10 ampere current, while that of a jet target is $7 \times 10^{8}$ with a proton density of $5 \times 10^{-7} \mathrm{~g} / \mathrm{cm}^{3}$ and a beam intensity of $10^{13} \mathrm{ppp}$. Thus, our rate 1 about $10^{5}$ higher than that of the ISR, We will have befter statistics and will be able to measure into the higher t-region where the cross section is smaller. The data of Fig. 1 ends around $|\mathrm{c}|=5(\mathrm{GeV} / \mathrm{c})^{2}$, and we will be able to extend these results to $|\mathrm{t}| \approx 10(\mathrm{GeV} / \mathrm{c})^{2}$. With future improvements in the jet target it may be possible to go to even higher momentum transfers.

\section{2, p-d Scattering}

The differential cross section for p-d elastic scattexing was measured up to 2 (GeV/c) ${ }^{2}$ at CERN using the PS up to $24 \mathrm{GeV} / \mathrm{c}, 6$ This result is shown in Fig. 3. The dip around $|t|=0.3$ has been investigated at lower energies extensivety in other laboratories, Recently, . Glaber has sugesested that it may be due to the strong dependence on polarisation of the deuteron spin and the d-state adeixture?. Beyond $2(\mathrm{GeV} / \mathrm{c})^{2}$ no data exists even at low energy. Only the Nat machine has the capability to investigate this region. 
From the p-d elastic scattering we can also deduce information about $p-n$ scattering, 8

\subsection{Isobar Production}

In the previously mentioned measurements of $p-p$ and $p-d$ elastic scattering, we will measure the momentum spectrum of the recoil protons. With sufficient resolution we can measture the cross sections for isobar production.

The production of isobars having masse"s of 1236, 1400,1520,1688, and $2190 \mathrm{MeV}$ in $\mathrm{p}-\mathrm{p}$ reactions has been investigated quite extensively up to $|t|=6(\mathrm{GeV} / \mathrm{c})^{2}$ and $P=24 \mathrm{GeV} / \mathrm{c} .{ }^{9}$ These results show that the differential cross sections for the 1520,1688 , and 2190 isobars have relatively small slope parameters $(b=3 \sim 5)$ and that they are comparable to that for elastic scattering around $|\mathrm{t}|=1(\mathrm{GeV} / \mathrm{c})^{3}$ as shown in Fig. 4. Moreover, the cross sections for producting these 1sobars are roughly s-independent up to $24 \mathrm{GeV} / \mathrm{c}$.

As shown in Fig. 9, our mass resolution on the recoil particle using only the recoll arm is good enough to separate the isobars at $100 \mathrm{GeV}$ beam energy for $0.2 \approx|c|<6(\mathrm{GeV} / \mathrm{c})^{2}$. At higher beam energies the separation of isobars becomes more difficult, especially between the 1520 and 1688 isobars. Thus, we expect to measure isobar production cross sections certainly at $100 \mathrm{GeV}$ and perhaps up to $300 \mathrm{GeV}$ in incident energy.

\section{Experimenta1 Setup}

The proposed experimental setup is shown in Fig. 5. A magnetic spectrometer is used to define the angle and momentum of the recoil particle and a 
Forward spectrometer is similarly employed for forward scattered particles. A set of monitors will also be provided in the turnel.

For the low $\mid \mathrm{t}$ | region as shown in Fig. 9, only the recoil spectrometer aeed be used. Its resolution is sufficient to define elastic events, especially at lower energies. For the higher ft| region, both spectrometers are used. Scintillation counter hodoscopes are used in the forward spectrometer; the angle information and the monentum of the forward particle are used together with the information from the recoll spectrometer to define the coplanarity and elasticity of the event. Four parameters are measured and the elasticity of the event is therefore over-defined (the momentum and the angle of a recoil particie, and of a forward scattered particle are measured).

\subsection{Recoil Particle_Spectrometer}

At large fixed angles momentum and twalue of elastic recoil particles change very litcle when the incident beam energy increases. The angle and the momentum of the recoll particle is shown in Fig. 6 for $300 \mathrm{GeV} / \mathrm{s}$ incident momentur. As was suggested in a noce by R. Carrigan, ${ }^{10}$ it is reasonabie to use a magnetic spectrometer where high t-values are studied. We propose to Jake a magnetic spectrometer with two bending magnets and a proportional chamber system for recoll particles in the $B=0$ section as shown in Fig. 7. We will be able to use this spectroneter up to $|\mathrm{t}|=15(\mathrm{GeV} / \mathrm{c})^{2}$ in steps of 5 degrees. The spectrometer consists of two magnets, four vertical and two horizontal proportional chamber planes and trigger counters. The relative position of these components to the target and beam line is 
show in Fig. 7. The whole system is mounted on a carriage and will be remotely rotated around the center of the target. The carriage supports two magnets, proportional chambers, trigger counters and some electronic circuits. There will be some provistion to change the relative angle of the two magnets on the carriage for different deflection angles. The first two wire planes define the incident angle of the recoil particle using only vertical wixes. They will be placed about 0.5 and 2.5 meters from the target. The vertical wires will have $1 \mathrm{~mm}$ spacing. The polar angle will be defined with an accuracy of $\sim \pm .4$ mrad. The recoll particle line will be extrapolated back to the target to check that it originated in the target.

There is a set of vertical and horizontal chembers between the two magnets, and another similar set two meters downstream from the second magnet. These also have one millimeter wire spacing vertically and two millineters spacing horizonta11y. The 6.3 and $2.9 \mathrm{GeV} / \mathrm{c}$ protons, coxresponding to $|t|=10$ and $4(\mathrm{GeV} / \mathrm{c})^{2}$, will be bent by 14.7 and $32.1^{\circ}$ at $18 \mathrm{~kg}$ respectively. The momentum resolution $(\Delta \mathrm{p} / \mathrm{p})$ will be about . IS and $.08 \%$ respectively.

The solid angle is defined by the scintillation counter $s 1$, which subtends about $2.2 \mathrm{msr}$ in the lab system and covers five degrees in the polar angle. The aperture at the entrance of the first bending magnet trust be $21.9 \mathrm{~cm}$ wide and $6.3 \mathrm{~cm}$ high to cover the solid angle. The apertures of the bending magnets are larger than these dimensions (5 inches high and 20 inches wide). The megnets bend the recoil particle in horizontal plane as 1ndicated in Fig. 7. The proposed shape of the magnet is shown in Fig. BA. It is almost a C-shaped magnet having only 
a thin yoke on the beam side whtch acts as a magnetic shield for the main ring and gives structural strength. Although we are describing conventional magnets, we should like to use super-conđucting magnets whenever they become feasible.

The solid angle defining counter $\$ 1$ is at the end of the spectrometer as is a second scintillation counter, S2. An absorber and a cherenkov counter are placed.between them. A signal derived from the coincidence of $S 1$ and $S 2$ will be used to register events into the computer. In addition, a coincidence is required with the RF structure of the main ring beam to avoid events not originating in the target. Fulse height in the Cherenkov' counter wili be recorded and used to help eliminate background due to piona.

Time of flight will be used at Low $t$-values only. The time of flight difference between a $2.9 \mathrm{GeV} / \mathrm{c}$ pion and a proton of the same momenturi $\left(|t|=4(\mathrm{GeV} / \mathrm{c})^{3}\right)$ is about i ns.

\subsection{Mass Resolutions}

Sieasuring only the recoil proton, the missing mass squared of the forward scattered particle is given by.

$$
\begin{aligned}
M^{2}= & m_{0}^{2}+2 r_{I}^{a}+2 m_{r}\left(E_{o}-E_{r}\right) \\
& -2\left(E_{0} E_{r}-P_{o} P_{r} \cos \theta_{r}\right) .
\end{aligned}
$$

Here the subscripts 0 and $r$ refer to the incident and recoil particles zespectively. Thus, the missing mass resolution can be estimated by taking

$$
\Delta M^{2}=\left[\left(\frac{\partial M^{2}}{\partial p_{0}}\right)^{a}\left(\Delta P_{0}\right)^{a}+\left(\frac{\partial M^{2}}{\partial P_{r}}\right)^{a}\left(\Delta p_{r}\right)^{2}+\left(\frac{\partial M^{2}}{\partial \theta_{x}}\right)^{a}\left(\Delta \theta_{r}\right)^{2}\right]^{\frac{1}{2}} .
$$




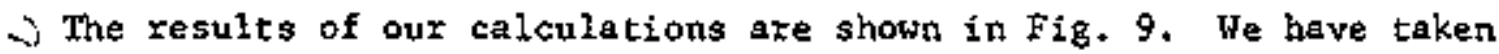
into account multiple scattering in the vacuum chamber windows and proportional chambers and also the position measurement exror in the chambers.

If we insist on having resolution better than the separation between the elastics and the " $N^{*}(1520)$, say $\Delta i^{2} \approx .7(\mathrm{GeV} / \mathrm{c})^{2}$ or $\Delta=370 \mathrm{MeV}$ then, as may be observed in Fig. 9, the can measure froxh $|t|=.2$ to $|\mathrm{t}|=10(\mathrm{GeV} / \mathrm{c})^{2}$ at $100 \mathrm{GeV} / \mathrm{c}$. At $300 \mathrm{GeV} / \mathrm{c}$ we can measure from $|t|=.3$ up to $|t| \approx 9.0(\mathrm{GeV} / \mathrm{c})^{3}$ with only the recoll spectrometer. At the higher energies and momentum transfer values both spectrometers are required to separate elastics from the $\mathrm{N}^{*} \cdot \mathrm{s}$. For exangle, at 300 and $400 \mathrm{GeV} / \mathrm{c}$ the forward spectrometer acceptance begins at $|\mathrm{t}|=1.0$ and $|\mathrm{t}|=1.8(\mathrm{GeV} / \mathrm{c})^{2}$ respectively. Thus, for energies below $300 \mathrm{GeV}$ we will measure the angular distribution starting at $|t|=.2$ and continue on up to about $|\mathrm{c}|=10(\mathrm{GeV} / \mathrm{c})^{3}$. At energies above $300 \mathrm{GeV}$ our measurements will begin at some lower cut-off $\left(\mathrm{e} . \mathrm{g}+3|\mathrm{t}|=1.8(\mathrm{GeV} / \mathrm{c})^{2}\right.$ at $400 \mathrm{GeV})$ and continue to the higher t-values.

\subsection{Fornard Particle Spectrometer}

As is shown in Fig. 10, the forward scattered particles at fixed angle have increasing momentum and t-values as the circulating bean energy increases. Therefore, the system at a fixed position with a fixed current measures elastic scattering for one energy only. The laboratory angle for the forward scattered particle at $|t|=4(\mathrm{GeV} / \mathrm{c})^{3}$ is $6.9,5.2$, and 4 nx for 300,400 , and 500 Gev beams respectively. 
The aystem congists of three bending magnets and four gets of seintillation counter hodoscopes as Indicated in Fig. 6. At 300 GeV the frotit end of the firat magnet is placod 19.1 maters downstream from the jet target in order to cover the t-regton from 4 to $10(\mathrm{GeV} / \mathrm{c})^{2}$. The current in the magnets as well as the position and angles of the magnets will be adjusted to accept only the elagtically scattered protons. The momentum acceptance, which should be sbout $0.5 \%$, can be eagily achieved and the necessary horizontal acceptance 1 e $2 \mathrm{mr}$. The solid angle Is defined by the recoll epectrometer.

The scintillation counter hodoecopes are before the firet magnet, betwen magneta, and aftẹ the last magnet in the forward spectrometer. There are al so some anticoincfdence counter. to veto partieles scattered from the steel surface and from the ourside. Each hodoacope consists of twelve horfzontal and six vertical acintillation counters. With the Information from the forward opectrometer the coplanartty and elaticity of the events wil be determined, and we can select the elastically acattered protong from the background. If noceasary, proportional chambers will be installed near the end of the forward apectrometer to improve resolution. For completeness we show the layout of the forward apectrometer for a different energy in FIg. 11.

The magnets axe ofmiliax to the-inatn ting magnets as far as aperture and length are concerned. The steel core is shaped lika the recoli spectroneter, as shown in $\mathrm{Fig}_{\mathrm{g}}$. BB. The outs1dedimensions will be about 28 inches high and 27 inches wad. 
The first maget has an aperture 1.5 1acheg high and 9.75 Inches wide with a 16 curn coll. The ingide yoke Is $1 / 4$ inch thick and the coll is 2.39 Inches wide. Therefore, the particle can go through the magnet at a mfnfmum distance of 2,64 inches from the outalde surface. The second and third magnets have an aperture 2.0 inches high and 8.73 Inches wide and 24 turn co1ls.

These magnets are connected in aerleg and axe exclted by the same power supply to a magnetic field of about $18 \mathrm{kG}$ wth $3500 \mathrm{Amp}$. The resistance of the firsc and second manets will be about 17 and $26 \mathrm{~m} \Omega$, The maximum total power consumption for these three magnets will be about $850 \mathrm{kN}$.

The nain ring vacuum pipe at Bo will be thifted inward by one inch relative to the center line connecting the upstream and downstream

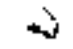
quadrupole magneto. The infected beam will be centered in this pipe wh th local'low fleld correction wegnets. However, the high energy bean will be set to tun 2 Inches from the outer aurface of the 6 inch pipe as ohown in Fig. 9B. At the extraction septum in to ts bet at $3 \mathrm{~cm}$ cutalde the center line and the abort target in Do to wet at 1.5 inches, thita would not seen to be a problem.

The use of a locel magnetic fleld beam bump at high energy will be considered. Whth this modification the beam will be shifted outward to make a lower t-region accessible fin the coincidence experiment.

\subsection{Konter}

We will install a vacuum gufde at right angles to the main ring beam 1ine, which is about 4 meterd long and covers laboratory angles 
roughly from 90 to 80 degrees. At the end of it will be installed several fixed solld Btate detectora which will be used to monttor small angle elastic events as was done in Experiment 36. These will be used as a relative luminosity monftor.

We wil also develop and Install an absolute luminoaity nonftor, vtilizing elther light emisaion due to the beam hydrogen gas tnteraction or coulomb scattering.

\section{Counting_Rates}

The density of the hydrogen jet is about $5 \times 10^{-7} \mathrm{~g} / \mathrm{cm}^{3}$. As the present beam Interaction region 18 about $1 \mathrm{~cm}^{3}$, we can asgume $\mathrm{N}_{t}=3 \times 10^{17}$ proton $/ \mathrm{cs}^{3}$ 1s available as our target. The fet duration tiare 18 about 200 ans, and 3 or 4 jet pulses in a main ring cycle are now possible. Also, the jet may be pulsed for one second continuousiy. We will operate the jet during the ramp for lower t-values. For higher t-values we may use the flat-top or front - porches of the main ring ramp.

The presently available beam intensity in the main ring is about $4 \times 10^{12}$ proton/pulse; th1s will be Increased eventually to $5 \times 10^{13}$ proton/pulse. For these calculations we assume $1 \times 10^{13}$ proton/pulse which may be a conservative value in the latter part of 1973. During a jet duretion of $200 \mathrm{~ms}$, the main ring besm circulates $10^{4}$ turns around the ring. So effectively, the avall. able beam during a jet pulse $18 \mathrm{H}=10^{4} \times 10^{13}=10^{17}$ proton/pulse. We wIl operate one jet at low energy and another at higher energy where the forward spectrometer is adjuated. He will operate 2 or 3 ject during flattop when it is feastble. 
The counting rate, $N$, per jet putse is given by the following equation:

$$
N=N_{b} N_{t} \frac{d g}{d t} \Delta t \frac{\Delta \varphi}{2 \pi}=3 \times 10^{34} \frac{d o}{d t} \Delta t \frac{\Delta \Phi}{2 \pi} / \text { jet pulae }
$$

$N$ is given in Table 3 , wh the estimated do/dt values from the presently $\therefore \quad$ available daca, si 18 given by $6.3 \mathrm{~cm} /(250 \mathrm{~cm} \times \sin \theta)$. The counting rate Is defined by the solid angle of the recoll partiele spectrometer stace the forward particle hodoacope is wade large enough to accommodate all the corresponding elastic events.

The Rusitan members of our collaboration are presently exploring the possibility of increasing the denatty of the jet for use at the highest c-values. One posalbility is to reduce the veloctcy of the jet and another 1a to develop a solid hydrogen target. With ouch modifications the jet density may be increased by a factor of 10 or more. On the other hand the beam Intensity may be raieed to $5 \times 10^{13}$ proton/pulse, With both these madiflcations the counting rate may be increased by a factor of 50 in the near future. Thus, the highest accessible t-value may be highor than discusaed in thla proposal.

\section{Background Rate}

There are two types of background: one target asaocketed and the other not. The background wilch doee not come from the target was measuzed in Msy $197 \mathrm{~s}$ at $300 \mathrm{GeV}$ to be about 16 minlmum ionizing particles $/ \mathrm{cm}^{2} / \mathrm{sec}^{10} 10$ circulating protons at 3.5 feet from the beam 11 ne. ${ }^{11}$ Thus, at $13 \mathrm{~cm}$ from the beam line and with $10^{13}$ circulating protong, the corxesponding number is $10^{6}$ particles $/ \mathrm{cm}^{2} / \mathrm{sec}$. Although this rate to tolerable for the forward hodoscope, it will be reduced by at least an order of magnitude. First of 
al1, the experimental area at B-0 will be designed more carefully so as not to restrict the cixculating beam. Secondly a beam scraper at Al7 and beam collimators at D-0 will used.

The effect of the accidental rate due to particles coming from the target can be estimated for the forvard spectrometer including the first forward hodoscope as follows. Th1s hodoscope is more seriously affected than the recoil spectroneter. We estimate the backgrownd rate at the $|\mathrm{t}|=4(\mathrm{GeV} / \mathrm{c})^{3}$ setting at $300 \mathrm{GeV}$. As there is a maximum of 1213 beam bunches in the main $x$ ing, we have $N_{b}=10^{20}$ proton/bunch for a beam intensity of $10^{13}$ ppp. The interval between beam bunches is about 20 ns and the total number of reactions during a bunch is estimated from a total cross section of $40 \mathrm{mb}$ as follows:

$$
N_{b} N_{t} \sigma_{t o t}=10^{10} \times 3 \times 10^{17} \times 40 \times 10^{-27}=120
$$

The raltiplicity measured by the bubble chamber is about 8.9 at $303 \mathrm{GeV}$, and the projected distribution in one dimension is shown in Fig. 12, where the events are grouped in $0.5 \mathrm{mr}$ bins. 12 Therefore, we have about 1000 charged particles coming from a jet target associated with a aingle beam bunch. The maximum nuber of particles going through the aperture of the first useftl magnet opening (which is $4 \mathrm{mr}$ horizontally and 1,5 inches high) is estimated to be less than 0.6\%. Thus, on the average, 6 particles may go through this opening; we can essily select the elastic scattered proton from the information given by the following counter hodoscopes. As these 1000 sharged particles may produce many low energy daughtex particles when they finally hit vacuum chambers and magnets, it is preferable to use a thin vacuum tube and also to place the counter hodoscope so that the back 
scattered particies reach the hodoscope out of phase with the scattered particles of interest, e.g., 10 ns later. The number of muons was measured In the $\infty$ area by Experiment $120 .{ }^{13}$ They observed $500 \mathrm{~m} / \mathrm{jet}$ ( $200 \mathrm{~ms}$ ) $110^{12}$ proton at $250 \mathrm{GeV}$ with a counter of $2 / 3^{\prime \prime} \times 2 / 3^{\prime \prime}$ placed at 16 mr and at 32 feet downstream from the jet. This gives $2.5 \times 10^{-3} /$ bunch $(=20$ ns $)$ $110^{13}$ proton/2 msr at $16 \mathrm{mr}$. This number will not cause difficulty for. this experinent.

\section{Comparisons with other Experiments}

In the future, elastic scattering will be measured at NAL using the external beam. However, we can measure the elastic scattering of p-p and $p-d$ in the main ring in a very flexible and efficient way. There are several advantages of the intermal target experiment over external target experiments for these reactions:

A. It is possible to select the tnctdent beam energy freely from the infection energy to the highest extraction energy. Thus the s-dependence measurement can be done easily and in a bias free way.

B. The internal target has che first access to the highest machine energy $\left(500^{\circ} \mathrm{GeV} / \mathrm{c}\right.$ or even $1000 \mathrm{GeV} / \mathrm{c}$ because no slow extraction is involved).

c. The target is thin, so that the multiple acattering of the recoti particle is small compared- to that of a liquid hydrogen target. Therefore, elastic scattering may be measured using only the recoll spectrometer over a large range of $t$ (FIg. 9). 
D. The Luminostty for the internal target is comparable to that of the external bean. For the internal target with 3 pulses of 200 ans width and a beam intensity of $10^{13} \mathrm{pPP}, I=N_{b} N_{t}=10^{13} \times 3 \times$ $10^{4} \times 5 \times 10^{-7} \times 6 \times 10^{23}=0.9 \times 10^{35}$. For the external beam with $4 \times 10^{11}$ ppp and 4" long liquid hydrogen target we have:

$$
L=N_{b} N_{t}=4 \times 10^{11} \times 4 \times 2.54 \times 0.071 \times 5 \times 10^{23}=1.7 \times 10^{35}
$$

E. At the intemal target the incident beam has no pion contamination; Identification of tncident particles using Cherenkov counter is therefore not necessary.

\section{Apparatus}

We are assuming the construction of the Bo internal target area will be started sometime In 1973. Allowing six months for construction of this sres, we expect the experimental area will be ready for accupation in early 1974. While the experimental area of the $B 0$ straight section and the gervice bulldigg are under corstruction, we will work on preparations for the experiment.

The major items which should be made or purchased during that time are:

A. BO general facility

1. Jet target

2. Control system for jet target

3. Helium liquifier, including dewars

4. Transfer line for helium

5. Recovery system of gases

6. Beam bumping, posstbly using local bunp magnets 
7. Monitors (beam intensity, beam position, elastic monitor, etc.)

8. Commuication system (TV, utility crate)

We assume NAL will supply all of these except for the jet target, whtch will be built by the Soviet collaborators. All of these are simlar to the equipment presently in $\mathrm{CO}$, and we expect all of it to be duplicated and completed in nine months.

B. Experimental equipment

1. Recoil spectrometer magrets

2. Forward spectrouleter magnets

3. Power supplies for spectrometers

4. Cooling systen for spectrometers

5. Fast logic circults

6. Proportional chamber system including Camac and its interface

7. Sctntillation counter hodoscopes

8. On-1ine PDP-11 system

We request NAL to supply the spectrometer magnets and power supplies as we11 as the cooling system. Purdue Uaiversity will build the proportional chambers and all scintillation counters. NAL will supply the readout electronics for the chambers, the FDP-11, Camac and its interface.

\section{Experimental Procedure}

We will first study $p-p$ and $p-d$ elastic and inelastic scattering in the lower trregion up to $4(\mathrm{GeV} / \mathrm{c})^{2}$ with continuous incident energies using only the recoil ant. For this phase of the expertment we need about 400 hours of running time. 
Next, using both the forward and racoil spectrometers, we will measure p-p elastic seattering in the high t-region with $200,300,400$ and possibly $500 \mathrm{GeV}$ beams. This experinent needs about 600 hours of runging.

Thus, we are requesting \& total of 1,000 hours of runting time for all experiments. Within one nonth after we move into the new service bulding, we will be able to start.the experiments. Members of our collaboration started the Co Internal Target Area and also helped carry out other experiments. This has provided a driving force in 60 and we expect to provide a similar oriving force in the new Bo Internal Target Area.

\section{Possible Future Experiments}

The elastic scattering experiment we propose to do should be the first experiment in the new Internal Target Area; it will provide data essential to understanding the apparatus for further experiments. Using the same equipant and with some; modifications the apparatus can also do the followIng experiments.

\section{$9.1 p+p \rightarrow p+$ anything}

$9.2 \quad \mathrm{p}+\mathrm{p} \rightarrow \mathrm{n}^{ \pm}+$anythíng

These two reactions will be very Lnceresting to study over the entire s-range. We can do these experiments by adding suitable Cherenkov counters to the recoil arm.

\subsection{Elastic scattering from some nuclei}

Elastlc scattering from some nuclej can be measured using the same equipment by observing the recoil malei with the low monentum spectrometer. 


\subsection{Polarization measuremenc}

A carbon polarizer can be placed after the first magnet of the recoil spectrometer in order to measure the left-right assymmetry with use of an extra set of wixe chambers. A polarization measurethent in the region around the dfp at $|\mathrm{c}|=1.3(\mathrm{GeV} / \mathrm{c})^{2}$ should help prọvide an understanding of the mechantsn responsible for the dip. $9.5 \mathrm{ptp} \rightarrow \pi^{+}+\mathrm{d}$

10. Manpower

In addftion to the physicists itsted on the title page, we expect one or more people from NAL and at least one graduate student from Purdue University to join the experiment when it is approved. 


\section{References}

1. V. Bartenev et. a1., P.R.L. 29, (1972) 1755.

2. R. Yamadz et. al., A.P.S. New York meeting, 1973.

3. U. Amaldi, CERN IP Internal Report 73-5, April 1973.

4. L. Durand III, and R. Lipes, P.R.L. 20, (I968) 637.

T. T. Chou and C. N. Yang, P.R.I. 20, (1968) $12 \mathrm{~L} 3$.

5. B. Malanud and W. Pelczarski, Proposal for a New Internal Target Hall.

6. F. Bradamante et. al., Phys. I,teters 32B, (1970) 303.

U: Amaldi et. a1., Nuclear Physics B39, (1972) 39.

7. V. Franco and R. J. Glauber, P.R.L. 22, (1969) 370.

8. J. Mmaldi et. al. knelear hysies 332, (1772) 39.

G. Jezongikn et. a1., "Detemination of Deuteron Form Factor From Exoermental Data on Elasicie p-d, p-p and n-p Scattering at Small Angles in the Energy Range of 10-26 geV". Dubna Preprint (1972).

9. J. V. Allaby et, al., Nuclear Physics 952, (1973) 316.

10. R. Carrigan's note "Extension of Proton Scattering Internal Target Techniques to Larger Momentum Iransfer" March 31, (1970).

11. J. Johnson. Private communication.

12. J. Schivell, Private conraunication.

13. R. Imlay. Erivate comminication. 
Table 1 - pp Elastjc scattering (at $300 \mathrm{GeV} / \mathrm{c}$ )

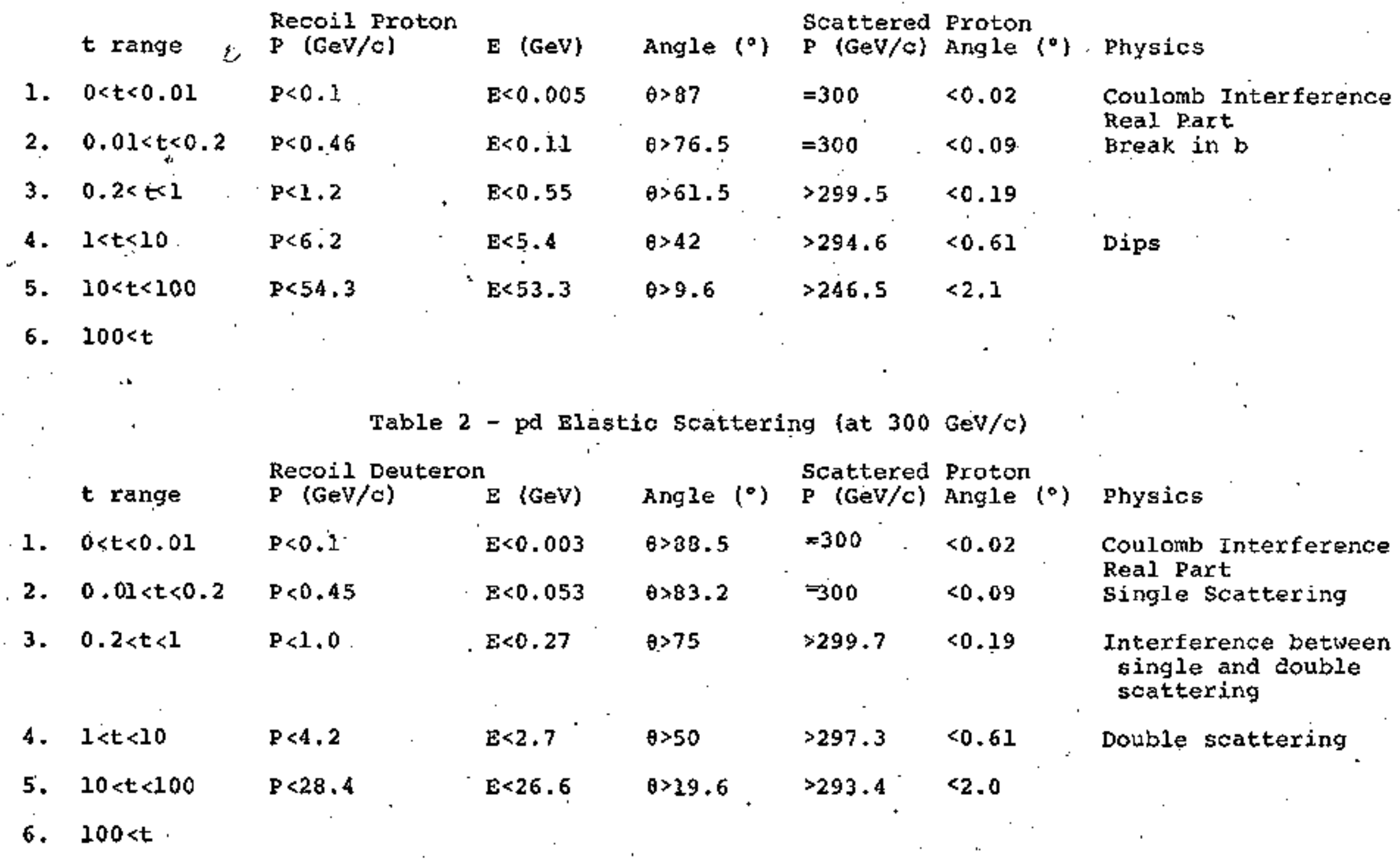


Table 3 Counting Rate

$$
N=3 \times 10^{17} \times 10^{4} \times 10^{13} \times \frac{d \sigma}{d t} \Delta t \frac{\Delta \phi}{2 \pi} / \text { jet pulse }
$$

pp Elastic Scattering

$\begin{array}{llllllll}|t| & d \sigma / d t & \Delta t & \theta & \sin \theta & \Delta \phi & N / j e t \text { pulse } & \text { N } / \text { day } \\ 3 & 1.5 \times 10^{-30} & 0.5 & 62^{\circ} & 0.88 & 0.028102 & 3.3 \times 10^{6} \\ 2 & 4 \times 10^{-32} & 0.8 & 52.5^{\circ} & 0.79 & 0.0324 .8 & 1.6 \times 10^{5} \\ 4 & 3 \times 10^{-33} & 1.7 & 43.5^{\circ} & 0.69 & 0.0360 .08 & 3.0 \times 10^{4} \\ 10 & 21 \times 10^{-36} & 4 & 30.3^{\circ} & 0.50 & 0.0500 .001 & 33\end{array}$

pa Elastic scattering
$16 \times 10^{-30}$
0.8
$75.5^{\circ}$
$0.97 \quad 0.026590$
$2.0 \times 10^{8}$
$2 \quad 1 \times 10^{-31}$
1.0
$69.3^{\circ}$
0.94
0.02712
$3.9 \times 10^{5}$
$4 \quad 25 \times 10^{-35}$
1.7
$61.5^{\circ}$
0.88
$\begin{array}{llll}0.028 & 0.01\end{array}$
$3.9 \times 10^{2}$

$\star \star$

Note 1 These counting rates will be increased by a factor of 50 in the future,as mentioned in the text due to the improvement of the main ring beam and the jet target.

Note 2 For this calculation we assume 5 sec for a main ring cycle and - three jets 'per pulse. Also we assume only two thirds of the total main ring pulses are avaliable due to the sublimation of jet and other miscellaneous things. 


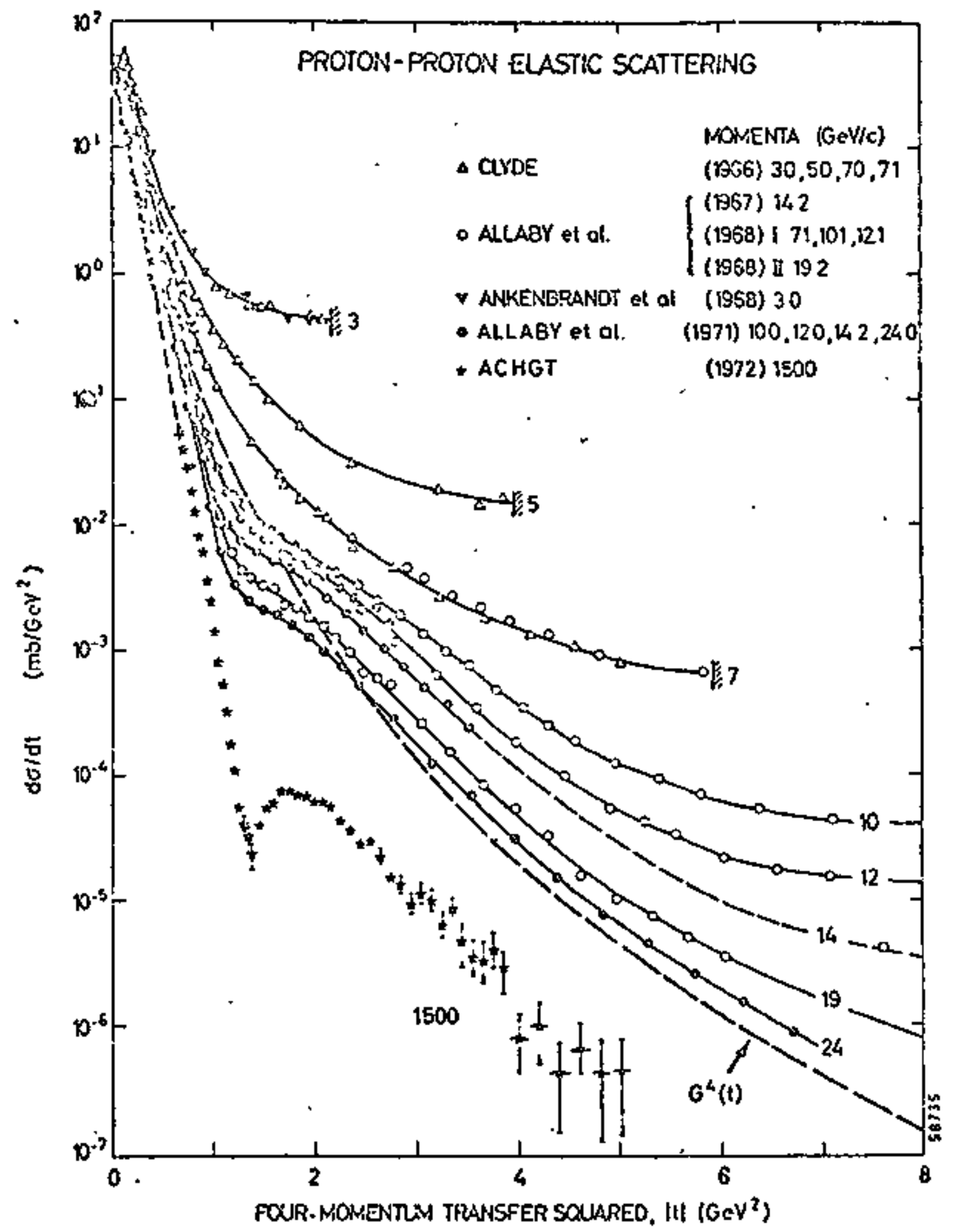

Fig. I Proton-Proton Elastic scattering 


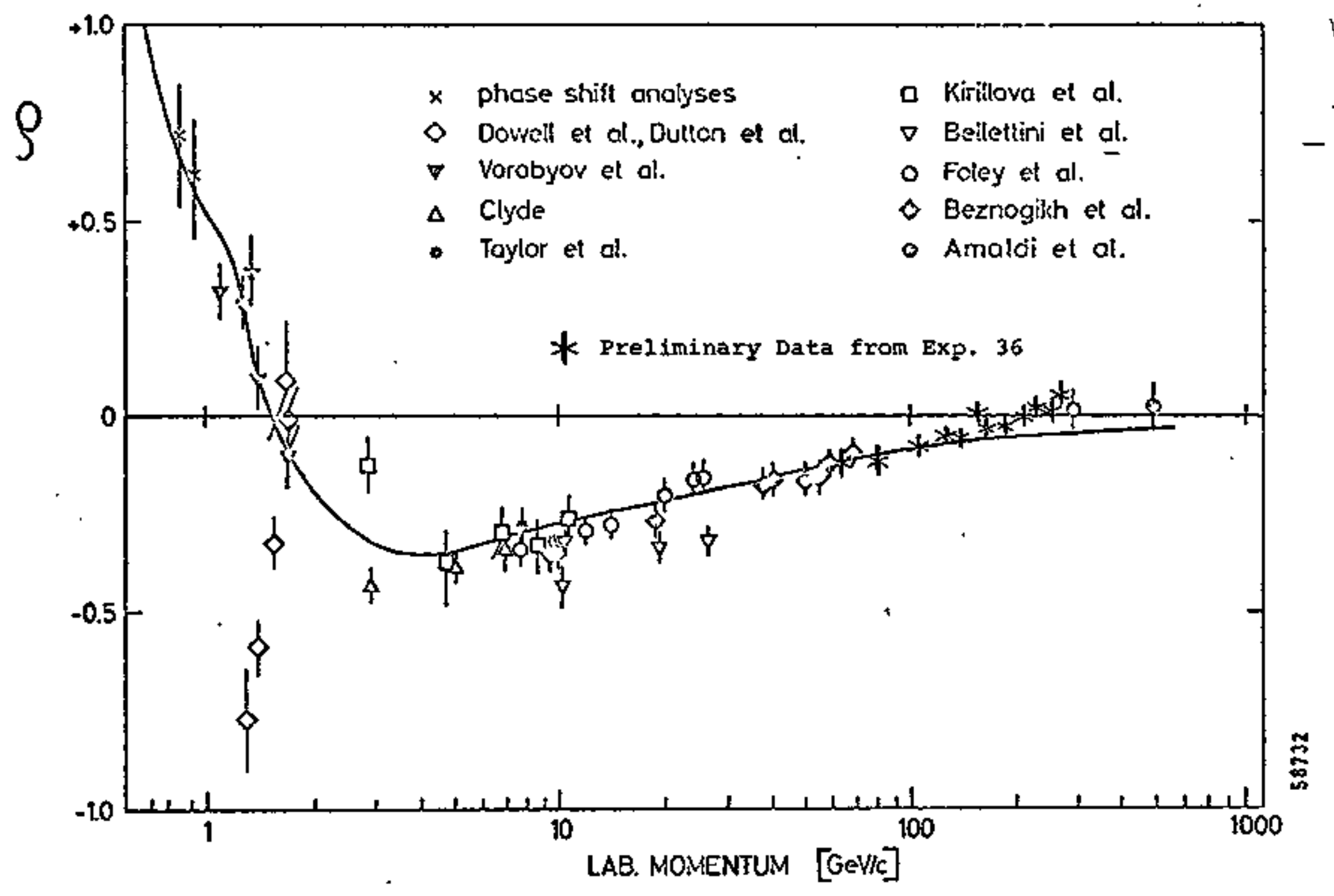

Fig. 2 Ratio of Real Part to Imaginary Part of scattering Amplitude 


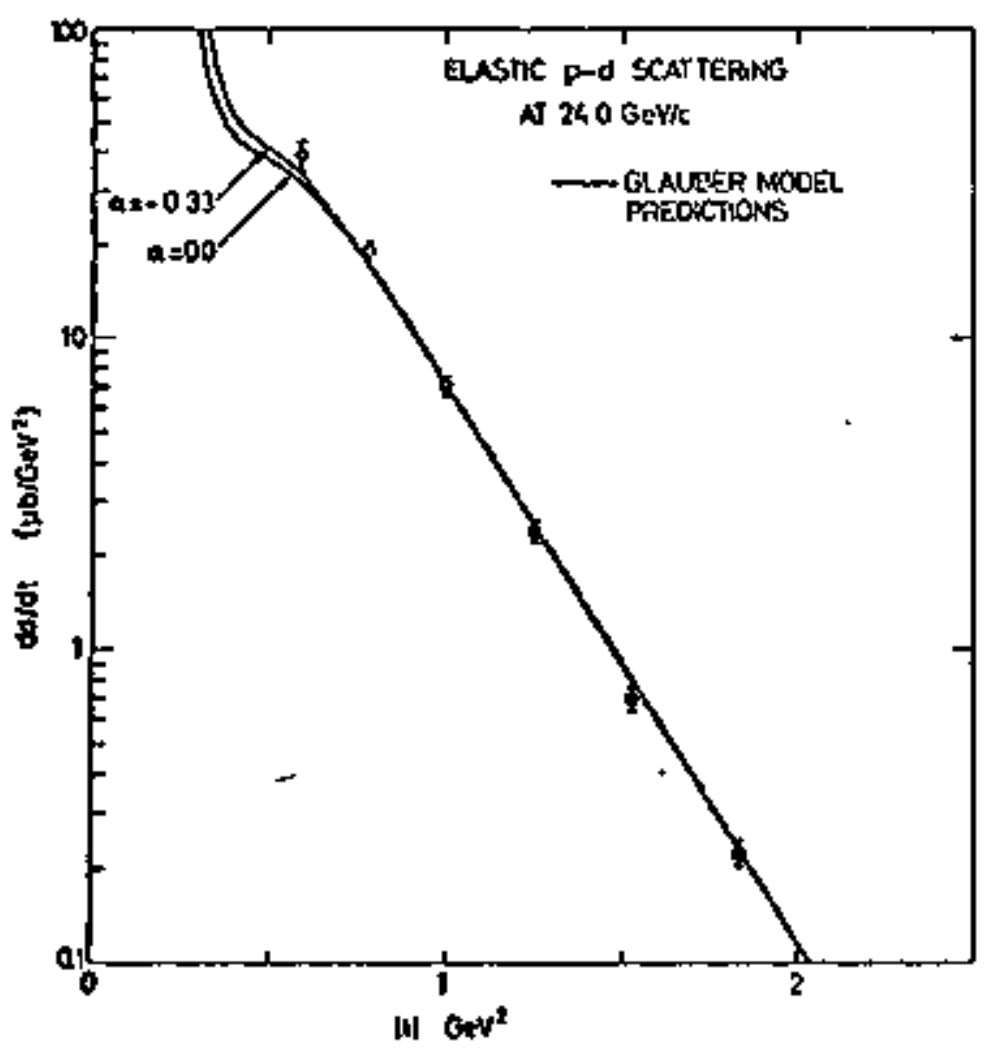

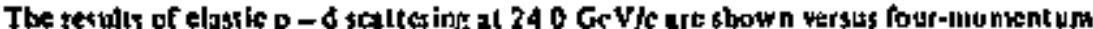

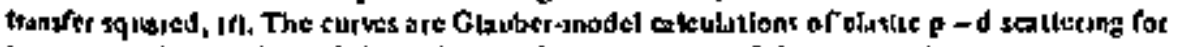

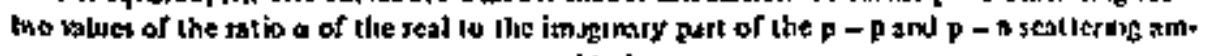
plitudc.

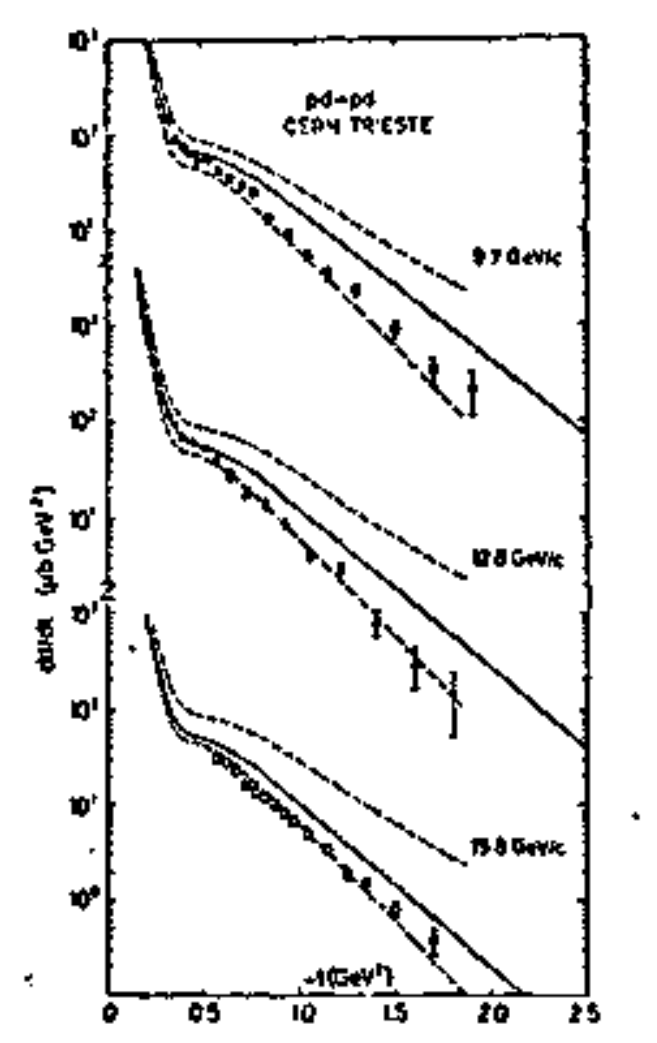

The pd etastic differctidit crost-section at

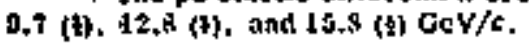

Fig. 3 p-d Elastic scattering 


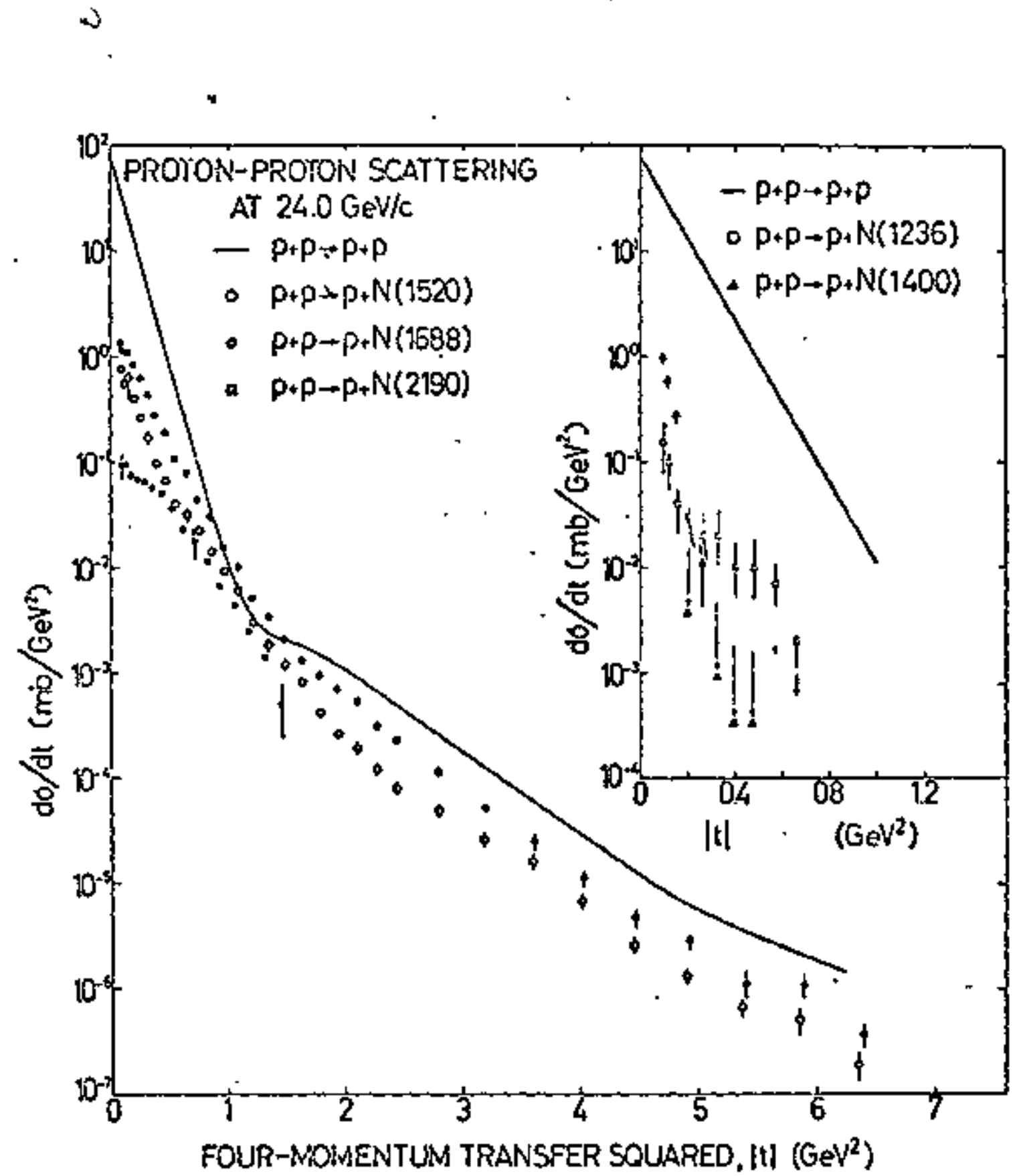

$\underset{N}{*}$

Fig. 4 Isobar Production at $24 \mathrm{GeV} / \mathrm{c}$ 
TWinEL PLAN VIEW

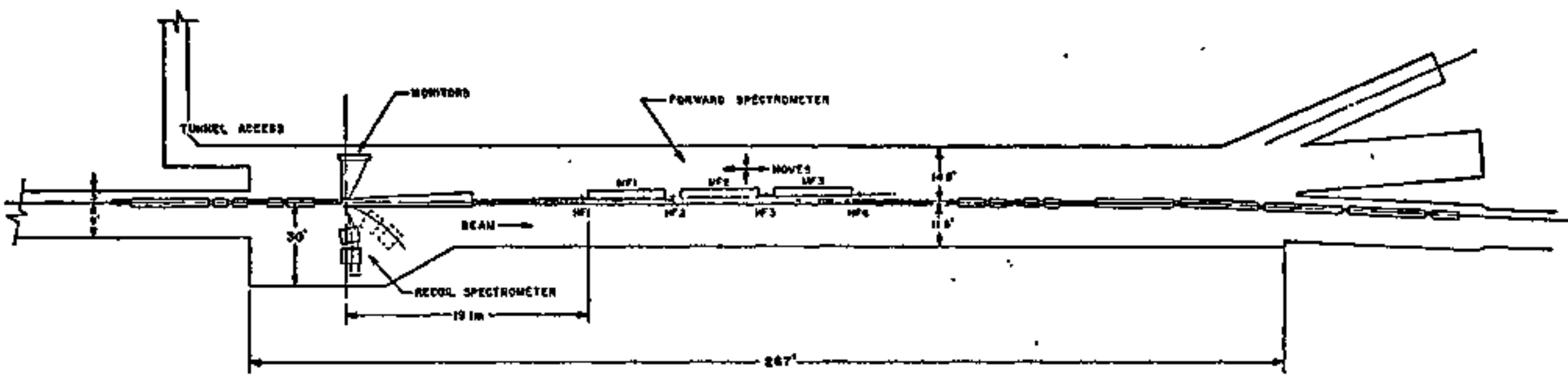

FIG.5 GENERAL LAYOUT OF PROPOSED EXPERIMENT N BO STRAIGAT SECTION 


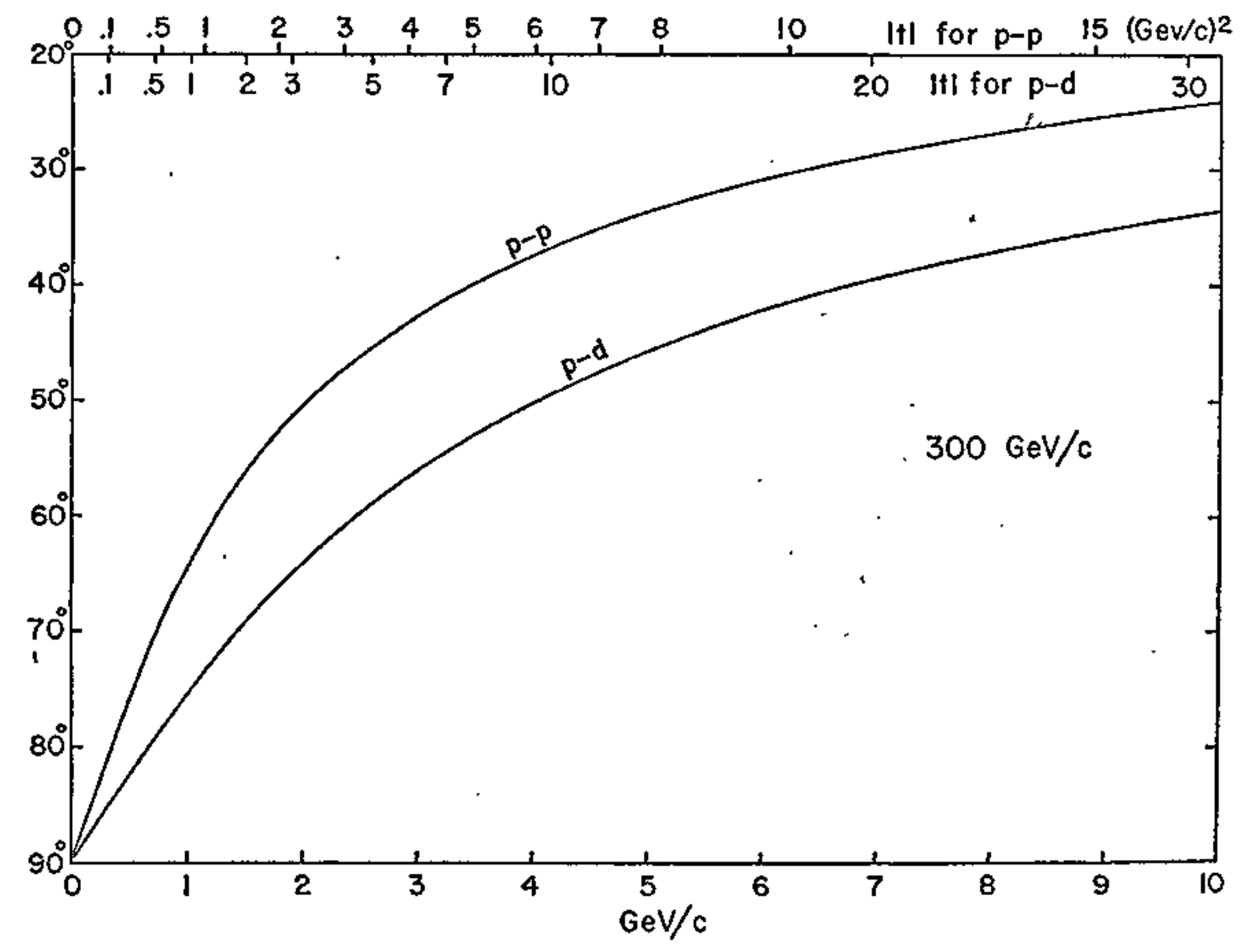

FIG. 6 KINEMATICS OF RECOIL PARTICLES 


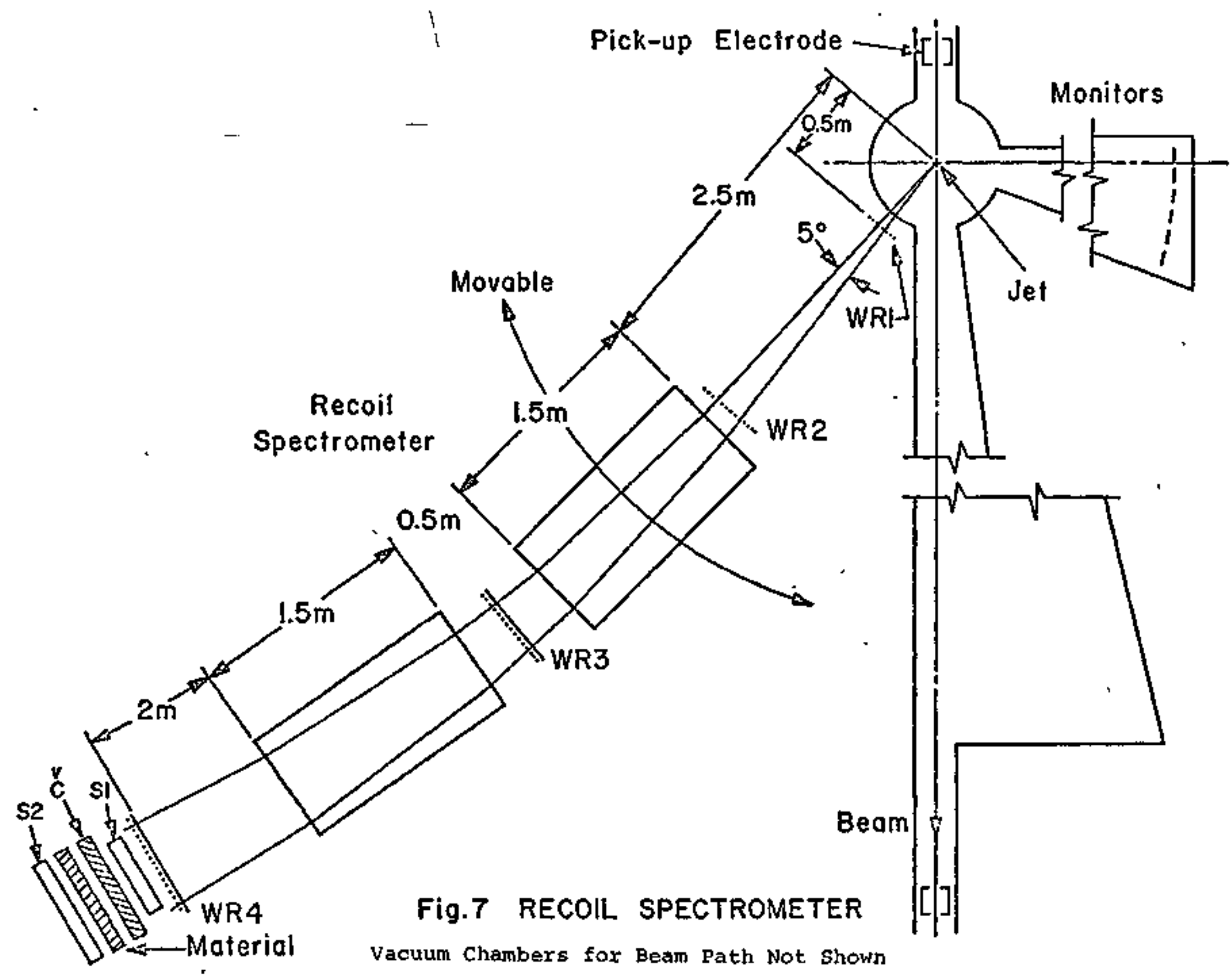




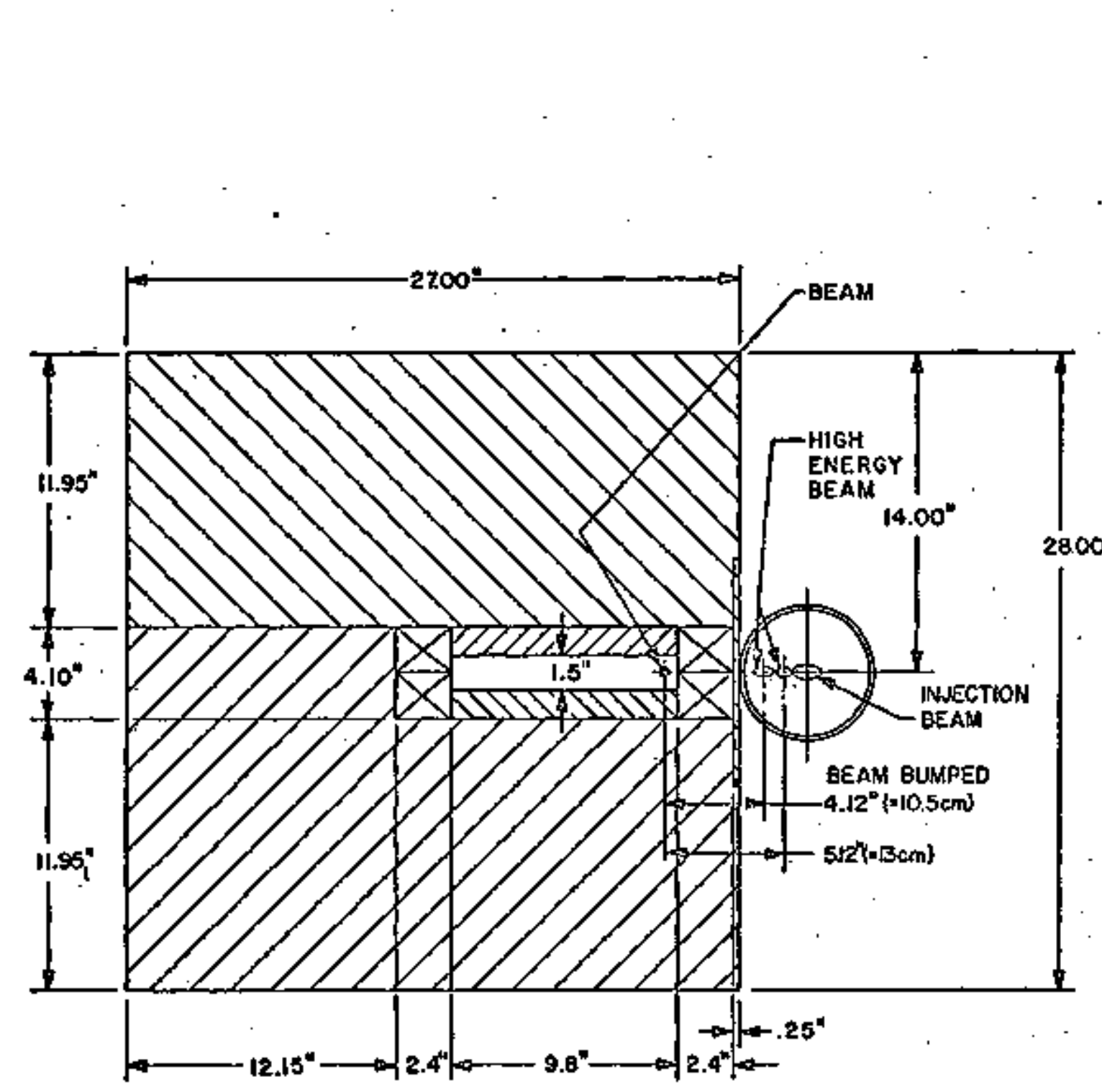

FIG. 89 CROSS SECTION Of FORWARD MAGNET

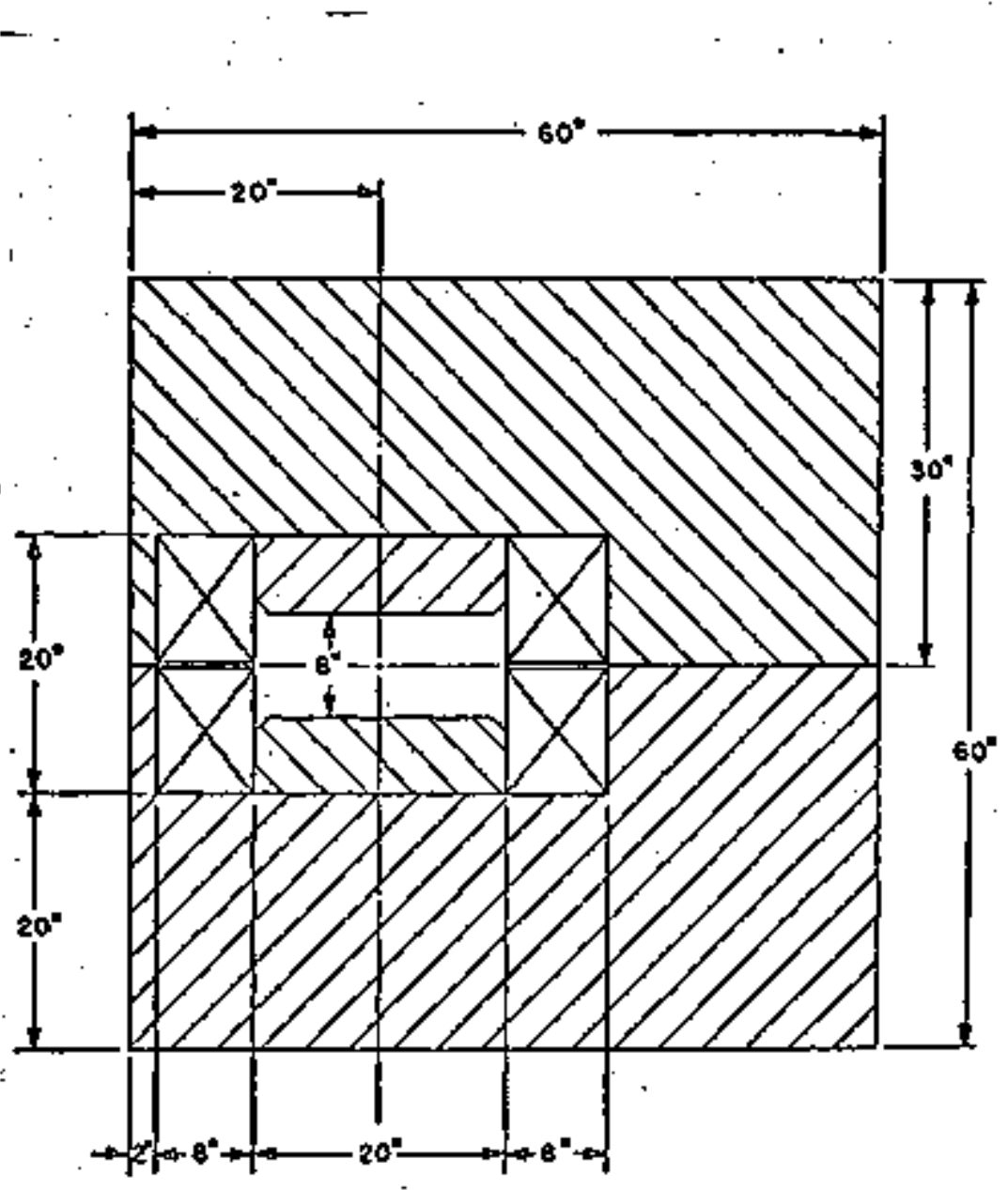

FIG. BA CROSS SECTION of RECOIL MAGNET 


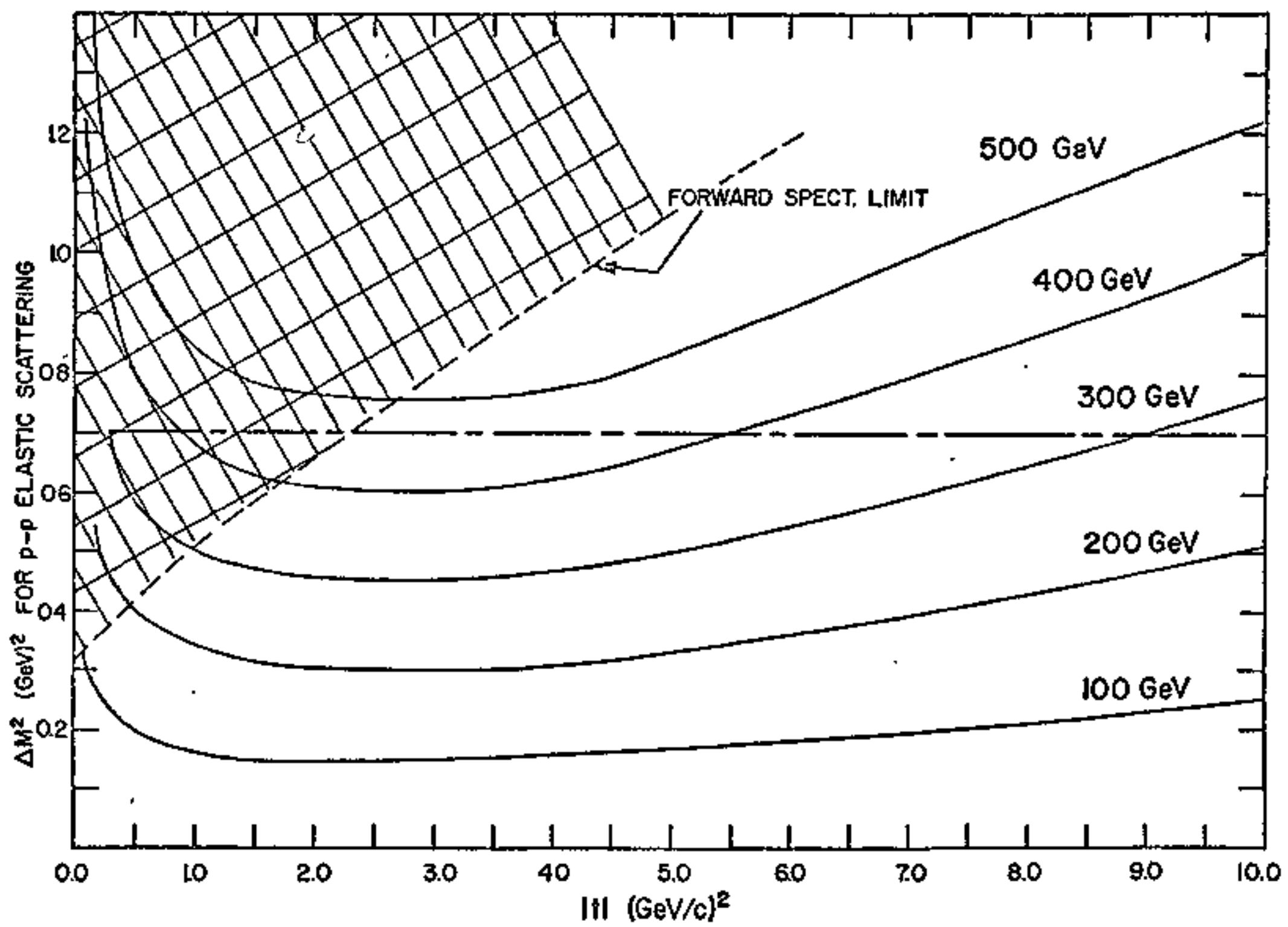

Figure 9A. Missing Mass Squared Resolution as a Function of $|t|$ for $p-p$ Elastic Scattering. The dashed line, represents the geometric boundary of the forward spectrometer. points below $\Delta \mathrm{M}^{2}=0.7$ (GeV) (broken line) are accessible with the recoil spectrometer only. Hence, only the crosshatched region is inaccessible to this experiment. 


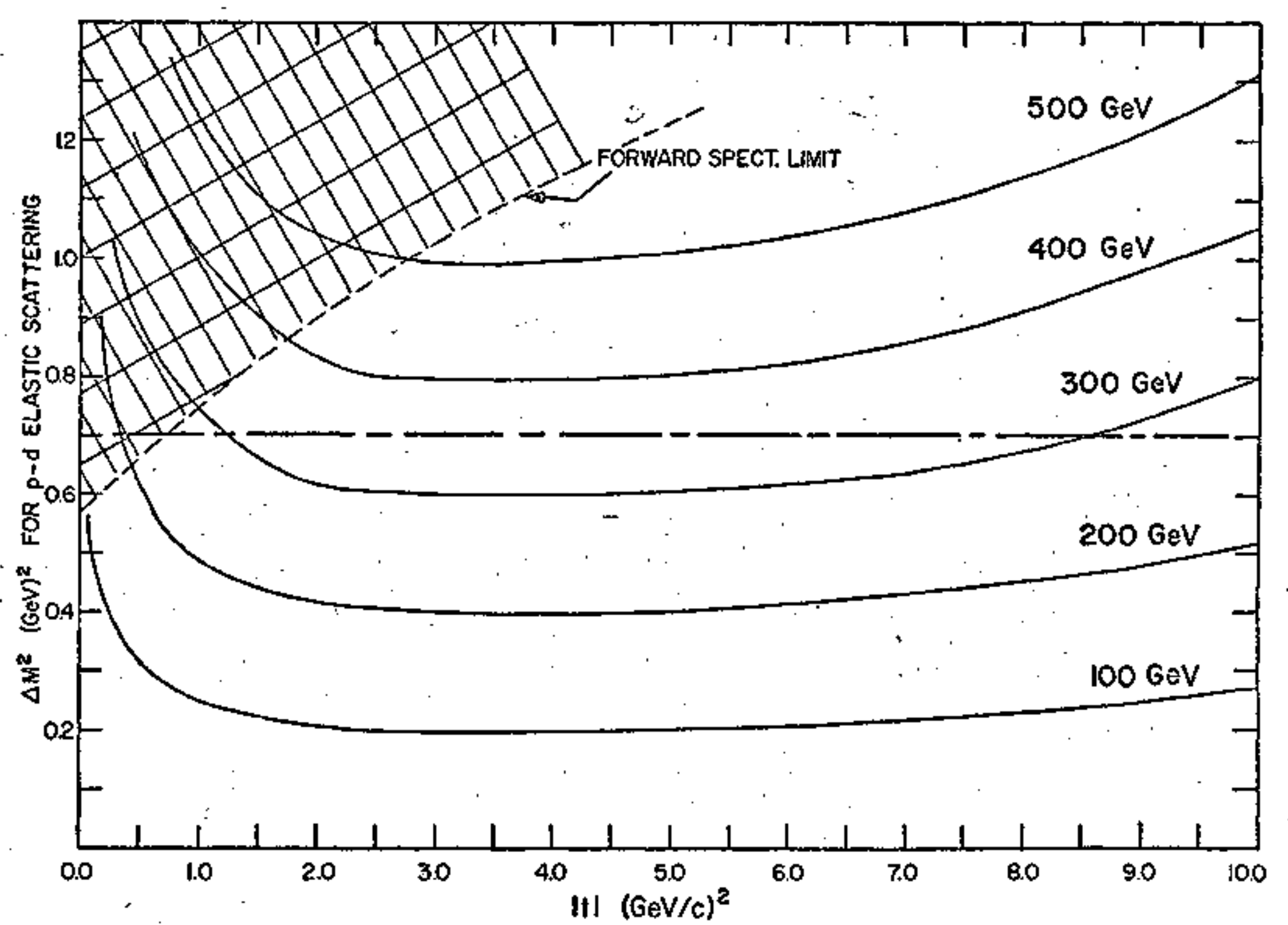

Figure 9B. Missing Mass squared Resolution as a Function |t| for p-d Elastic scattering.

The dashed line represents, the geometric boundary of the forward spectrometer. Points below $\Delta M^{2}=0.7$ (GeV) ${ }^{2}$ (broken line) are accessible with the recoil spectrometex only. Hence, only the crosshatched region is inaccessible to this experiment. 


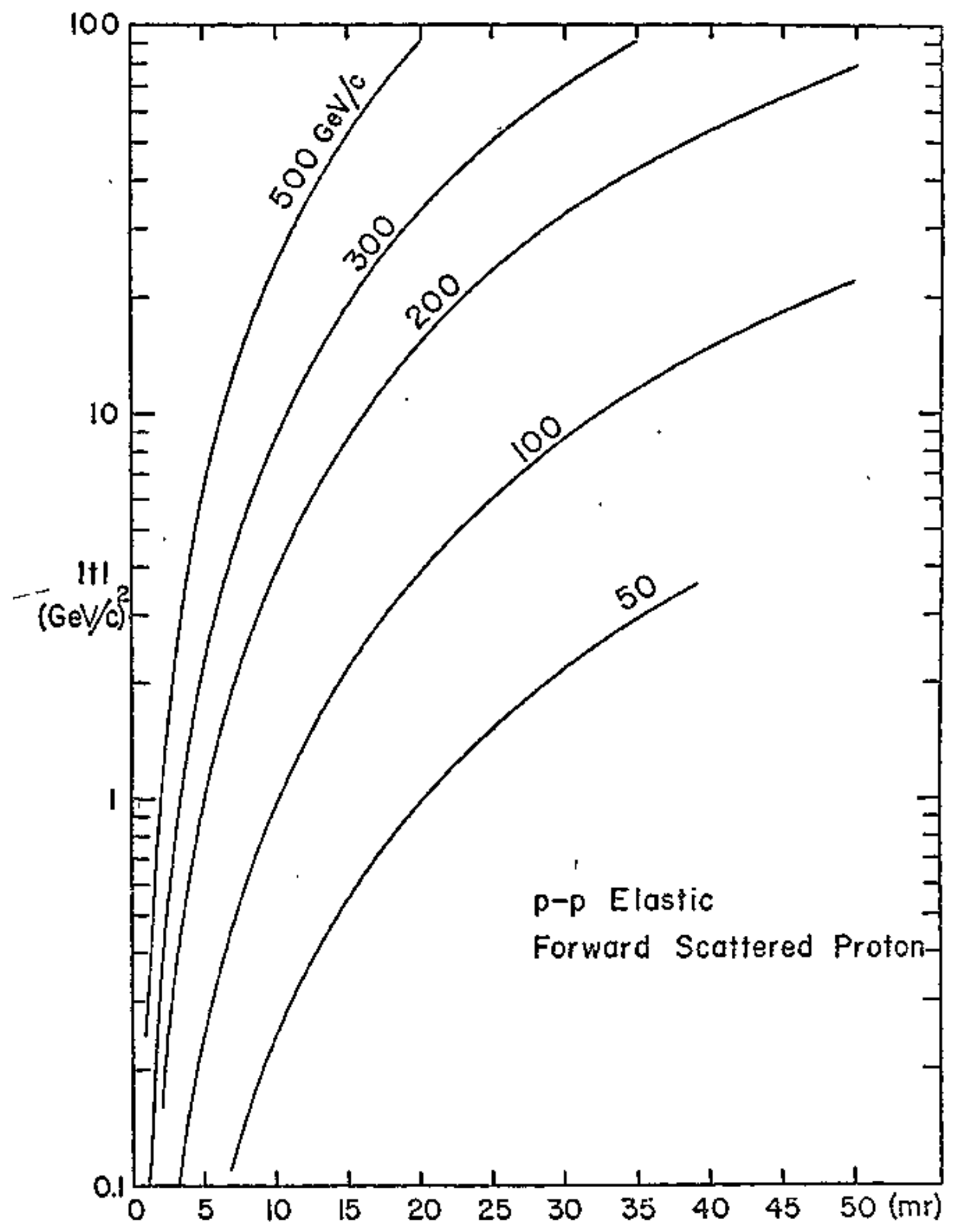

FIG. 10 KINEMATICS OF FORWARD SCATTERED PROTON 


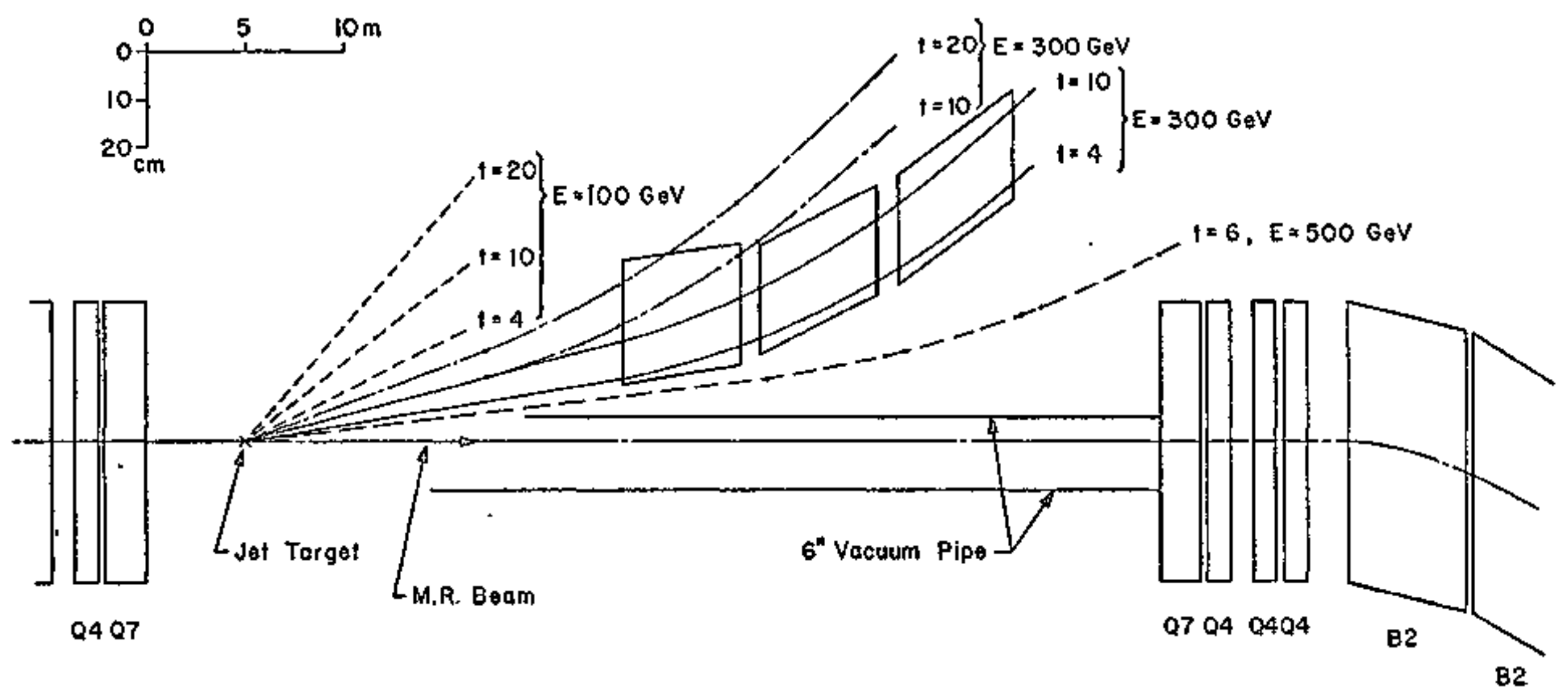

Fig. II Position of Forward Spectrometer 
